attach themselves to anything but heavy bodies" (Royal Commission on Coast Erosion, Ans. 4059).

A steady current has often no disturbing effect on the sea bottom, as the upper strata slide over the lower ones, but the slightest wave-action on the bottom, with its alternating currents, is most effective; and, as Sir George Stokes pointed out (I believe for the first time), the combined action of wave and tidal current may be very energetic, as in the case he cites, in which the combination of a steady tidal current of two miles an hour, combined with a reciprocating flow of one mile, would result "in a flow rapidly changing between one mile and three miles." I doubt whether this important fact had ever occurred to anyone else; and, up to the present time, no one has taken any notice of it, so far as I am aware.

Torquay.

A. R. Hunt.

\section{Two Notes from India.}

I AM writing to report a rather curious freak lily which I have lately seen out here. It was a garden variety, and it possessed a perianth of eight segments, which, however, is not unusual, but it also possessed eight stamens, the anthers of which were joined together in pairs, the remainders of these organs being separate. The union began about two-thirds of the way down from their apices, and from then up was complete. If any of your readers can suggest a cause I shall be glad to know it; I have never seen such a condition before. I may say that the rest of the organs were normal (there was only one flower on the plant), and both flower and plant were very healthy.

The second note which I might record as well, I think, though I know my statements about it will perhaps make some people doubt my veracity, is that while on duty one day, in the evening, about twenty miles away from Sangor, Central Provinces, in January a year ago, I was driving back through the jungle to Sangor about 7.30 p.m. when I distinctly saw what I consider to be an aurora borealis. The sun had set, and there was no moon out at the time. Suddenly faint streaks, and later distinct and many bright streaks, of light appeared across the sky, and I got out of the tonga and watched it about a quarter of an hour. There was continual vibration and movement of the light as a whole and of individual parts. The light was a plain white one, and very like a zig-zagged comb. No lights of any kind were near, nor could I see the fires or lights of any native villages except faintly in the distance, and these were quite distinct and easily distinguished from the sky phenomena. I pointed it out to my tonga wallah, who shook his head and said he did not know what it was. The stars were out, but that it was not a planetary light I am certain. I imagine the occurrence of this phenomena must be most uncommon in cropical countries, and I noted it in my diary.

J. H. BARBOUR.

Jubbulpore, Central Provinces, India, October 20.

\section{Instruction in Methods of Research.}

IN Nature of November 3 appeared an address by Sir IV. A. Tilden on modern scientific research.

The technical chemist may hardly agree with his conclusions that the art of scientific discovery cannot be communicated from one person to the other when the matter is considered in its wider aspect, and although it may be true that the great discoveries of the future will be made by the "inspired amateur," yet there is plenty of evidence that in Germany, at any rate, the general increase of knowledge and progress is to a great extent made up in detail work, without which it may also be stated that the great discoveries would never be made. Progress in this detail work to a great extent seems to be influenced, if not controlled, by training in research.

It is interesting to note that some authorities seem to have the impression that in this country the proportion of research men to chemists is higher than abroad.

In the columns of NATURE and elsewhere I have previously advocated the teaching of the principles of research in class in all our chief colleges, and I believe that NO. 2 I 42 , VOL. 85$]$ the student when entering them looks for some such training and expects it. This training would be of great value to the majority of chemists, who will naturally find their future work in industry. Its influence must be felt in the conduct of their future work.

The greater part of the time of the industrial chemist is taken up with dealing with unseen difficulties and overcoming them. This may not be research in its proper sense, but these difficulties can only be overcome in one way, and this when examined in detail will be found to be very similar, if not identical, with that necessary for the conduct of research. In fact, such work might be defined as the application of such principles of research to industry. It is not the application of ordinary academic chemical knowledge. That is certain.

So that with such a training, I would venture to point out, the man who has not that "combination of mental powers which is called insight" will derive great benefit, for it seems difficult to think that the student who has passed the entrance examination and gone through the college course can be entirely devoid of some such quality, even if he has not it to a superlative degree. The latter men must be trained, for has not Newton said that " zeal without knowledge is like expedition to a man in the dark"?

Some two years ago I put the question Sir William Tilden mentions of the establishment of central research stations for the chief industries before a textile society in the north.

It was then suggested that there were many difficulties in the way of a technical nature. One of the advantages of such a scheme would consist of the training which might be given to the younger men who are entering industrial work, and it may be that this could, to a great extent take the place of the practical training in the colleges themselves, which Sir William Tilden, perhaps rightly, depreciates when it is carried too far.

Royal Societies Club, St. James's Street, S.W. November 5 .

\section{The Armour of Stegosaurus.}

PARDON me for saying that there is not the slightest reason to believe that the restoration of Stegosaurus with a double row of plates is incorrect, in spite of the statement of the reviewer in Nature for October 13. Not a single plate of this animal has been found with a symmetrical base, the base always being at an angle to the vertical axis of the plate; this implies that the plates were not placed on the median line, but to one side of it. Furthermore, in the only specimen in which anything like a complete series of plates has been preserved the linear extent of these plates is, roughly speaking, 40 feet, and it is a physical impossibility to arrange them in one series on 20 feet of back. These plates lie in position overlapping one another.

The only point at issue between Dr. Lull, who has studied the Stegosaurs most carefuily, and myself is in regard to the arrangement of the plates. Dr. Lull believes that they were arranged in pairs. My own view is that, reasoning by analogy, they should have been thus arranged, but the facts in the case point to their having been placed alternately on opposite sides of the median line. No pair of plates has ever been found, and, making the greatest allowance possible for individual variation, it seems incredible that differences of several inches should exist between the plates from the two sides of the body if they were arranged in symmetrical pairs.

Museum of the Brooklyn Institute.

F. A. Lucas.

THE above letter from $\mathrm{Mr}$. F. A. Lucas shows that my apologies are due to the author of "Extinct Monsters and Creatures of Other Days." It is Marsh's restoration of Stegosaurus with a single row of dorsal plates that is incorrect, as was pointed out in a notice of Dr. Lull's restoration in the American Journal of Science for March, I910, in NATURE for the present year. In writing the review of Mr. Hutchinson's volume I must have trusted to memory, which played me false. $R, I$. 